\title{
Factors Associated with Early Hospital Arrival in Patients with Acute Ischemic Stroke
}

\author{
Dongbeom Song, ${ }^{\mathrm{a}}$ Eijirou Tanaka, ${ }^{\mathrm{b}}$ Kijeong Lee, ${ }^{\mathrm{a}}$ Shoichiro Sato, ${ }^{\mathrm{b}}$ Masatoshi Koga, ${ }^{\mathrm{b}}$ Young Dae Kim, ${ }^{\mathrm{a}}$ \\ Kazuyuki Nagatsuka, ${ }^{c}$ Kazunori Toyoda, ${ }^{b}$ Ji Hoe $\mathrm{Heo}^{\mathrm{a}}$ \\ ${ }^{a}$ Departments of Neurology, Severance Stroke Center, Yonsei University College of Medicine, Seoul, Korea \\ 'Department of Cerebrovascular Medicine, National Cerebral and Cardiovascular Center, Suita, Osaka, Japan \\ 'Department of Neurology, National Cerebral and Cardiovascular Center, Suita, Osaka, Japan
}

Background and Purpose Factors associated with early arrival may vary according to the characteristics of the hospital. We investigated the factors associated with early hospital arrival in two different stroke centers located in Korea and Japan.

Methods Consecutive patients with ischemic stroke arrived hospital within 48 hours of onset between January 2011 and December 2012 were identified and the clinical and time variables were retrieved from the prospective stroke registries of Severance Hospital of Yonsei University Health System (YUHS; Seoul, Korea) and National Cerebral and Cardiovascular Center (NCVC; Osaka, Japan). Subjects were dichotomized into early (time from onset to arrival $\leq 4.5$ hours) and late ( $>4.5$ hours) arrival groups. Univariate and multivariate analyses were performed to evaluate factors associated with early hospital arrival.

Results A total of 1,966 subjects (992 from YUHS; 974 from NCVC) were included in this study. The median time from onset to arrival was 6.1 hours [interquartile range, 1.7-17.8 hours]. In multivariate analysis, the factors associated with early arrival were atrial fibrillation (Odds ratio [OR], 1.505; 95\% confidence interval [CI], [1.168-1.939]), higher initial National Institute of Health Stroke Scale scores (OR, 1.037; 95\% Cl [1.023-1.051]), onset during daytime (OR, 2.799; 95\% $\mathrm{Cl}$ [2.173-3.605]), and transport by an emergency medical service $(\mathrm{OR}, 2.127 ; 95 \% \mathrm{Cl}[1.700-2.661])$. These factors were consistently associated with early arrival in both hospitals.

Conclusions Despite differences between the hospitals, there were common factors related to early arrival. Efforts to identify and modify these factors may promote early hospital arrival and improve stroke outcome.

Keywords Acute stroke therapy; Cerebral infarction; Early hospital arrival; Prehospital delay; Emergency medical service; Countries

\author{
Correspondence: Ji Hoe Heo \\ Department of Neurology, Yonsei \\ University College of Medicine, \\ 50 Yonsei-ro, Seodaemoon-gu, \\ Seoul 120-752, Korea \\ Tel: +82-2-2228-1605 \\ Fax: +82-2-393-0705 \\ E-mail: jhheo@yuhs.ac
}

Received: January 23, 2015 Revised: March 31, 2015 Accepted: April 1, 2015

This work was supported by a grant from the Korea Healthcare Technology Research and Development Project, Ministry for Health and Welfare, Republic of Korea (HI10C2020, HI08C2149). The NCVC Stroke Registry is partially supported by an Intramural Research Fund (H23-4-3) for Cardiovascular Diseases of National Cerebral and Cardiovascular Center.

Shoichiro sato holds a fellowship from the vehara Memorial Foundation of Japan.

\section{Introduction}

Administration of intravenous (IV) tissue plasminogen activator (tPA) within 4.5 hours, ${ }^{1}$ and endovascular reperfusion therapy within 6 hours $^{2}$ are the proven treatments for acute ischemic stroke. However, only a small proportion of patients with isch- emic stroke receive reperfusion therapy, mainly because of the narrow time window. ${ }^{3,4}$ Delayed presentation at hospitals is one of the most important factors hindering reperfusion therapy. ${ }^{3}$ Even within the therapeutic time window, the benefit is strongly time-dependent. ${ }^{5,6}$ Therefore, early hospital arrival is important to improve outcome of patients with ischemic stroke. 
In an effort to promote early hospital arrival, several studies have been conducted to determine the factors associated with early hospital arrival, and have identified demographic, socioeconomic, clinical, and personal characteristics related to early hospital arrival. ${ }^{4,7-10}$ Early hospital arrival has been associated with socioeconomic status and the prehospital delivery system, and may involve factors that differ according to the characteristics of the country or hospital. Therefore, we investigated the factors associated with early hospital arrival using data of two stroke centers with distinct characteristics, which are located in urban areas of Korea and Japan.

\section{Methods}

\section{Study hospital and patients}

This is a retrospective cohort study. Data were obtained from the prospective stroke registries of Severance Hospital of the Yonsei University Health System (YUHS, Seoul, Korea) and the National Cerebral and Cardiovascular Center (NCVC, Osaka, Japan; ClinicalTrials.gov Identifier: NCT02251665). Consecutive patients with ischemic stroke who had arrived at hospital within 48 hours ( 24 hours for sensitivity analyses) of symptom onset were included in this study. We excluded patients who had a stroke while they were being hospitalized. The study period was from January 2011 to December 2012. Severance Hospital of the YUHS is a 2000-bed, typical university general hospital located in the central part of Seoul, the capital city of Korea. The NCVC is a 640bed hospital specializing in cerebrovascular and cardiovascular diseases, and is located in the northern part of Suita city in Osaka prefecture, which is the second largest metropolitan area in Japan. The stroke centers of the YUHS and NCVC satisfy the key requirements for a comprehensive stroke center, as defined by the Brain Attack Coalition. ${ }^{11}$ The Institutional Review Boards of the YUHS and NCVC approved this study and granted a waiver of consent because of the retrospective nature of the study.

\section{Variables and groups}

The onset time of stroke symptoms, time of arrival at the hospital, demographic data, mode of transport, vascular risk factors, and initial National Institute of Health Stroke Scale (NIHSS) score were all retrieved. For patients whose onset of symptoms was unknown, the last known time without symptoms was regarded as the time of symptom onset. The onset time was categorized into weekday (Monday to Friday) vs. weekend (Saturday, Sunday, and official holidays in each country), and daytime (06:01-22:00) vs. nighttime (22:01-06:00). Mode of transport was classified into emergency medical services (EMS) vs. others (e.g., private car, taxi, walking). Stroke symptoms were retrieved from NIHSS sub-scales. Each NIHSS sub-scale was categorized as either normal (score $=0)$ or abnormal (score $>0$ ). Right and left arm motor scores were combined as "arm weakness," and right and left leg motor scores were combined as "leg weakness." Subjects were dichotomized into the early group (time from symptom onset to hospital arrival $\leq 4.5$ hours) and the late group (time from symptom onset to hospital arrival $>4.5$ hours). The cut-off value of 4.5 hours was chosen considering the current 4.5 hours time limit of IV $\mathrm{tPA}^{1}$ and the possible endovascular reperfusion therapy time window of 6 hours from onset to puncture. ${ }^{2}$

\section{Statistical analysis}

Values were presented as number (\%), mean \pm standard deviation $(\mathrm{SD})$, or median with interquartile range [IQR], as appropriate. Univariate analyses (independent sample $t$ test or MannWhitney U test for continuous variables, and $\chi^{2}$ test or Fisher's exact test for categorical variables, as appropriate) were performed to compare demographics, past history, previous medications, stroke symptoms, onset time, and transfer mode between the early and late arrival groups. Variables achieving a $P$ value of $<0.1$ in the univariate analyses for early hospital arrival were adjusted for multivariate analyses except for each stroke symptom because of potential collinearity with total NIHSS score. Statistical analyses were performed using the IBM SPSS Statistics for Windows Version 20.0 (IBM Corp., Armonk, NY, USA). A two-sided $P$ value of $<0.05$ was considered statistically significant.

\section{Results}

\section{Baseline characteristics}

There were 2,047 patients with ischemic stroke (1,228 from YUHS; 1,199 from NCVC) between January 2,011 and December 2,012. From these, 2,009 patients (1,016 from YUHS; 993 from NCVC) who arrived at hospital within 48 hours of symptom onset were considered for this study. We excluded further 43 patients ( 24 from YUHS; 19 from NCVC) who had in-hospital stroke. Finally, a total of 1,966 subjects (992 from YUHS; 974 from NCVC) were included in the study. Mean age was 70.0 \pm 13.1 years and $60 \%$ were male. Median time from symptom onset to hospital arrival was 6.1 hours [IQR, 1.7-17.8 hours].

Comparisons of baseline characteristics between the two hospitals showed that patients with stroke at the NCVC were older, and had the following characteristics: lower body mass index and abdominal circumference; more frequent history of hypertension, atrial fibrillation, hypercholesterolemia, previous stroke, previous use of anticoagulant drugs; less frequent history of diabetes mellitus and previous use of antiplatelet agent and lipid 
Table 1. Baseline characteristics of patients from the YUHS and NCVC

\begin{tabular}{|c|c|c|c|c|}
\hline & $\begin{array}{c}\text { Total } \\
(\mathrm{n}=1,966)\end{array}$ & $\begin{array}{c}\text { YUHS } \\
(n=992)\end{array}$ & $\begin{array}{c}\text { NCVC } \\
(n=974)\end{array}$ & $P$ \\
\hline \multicolumn{5}{|l|}{ Demographics } \\
\hline Sex (male) & $1,180(60.1)$ & $600(60.6)$ & $580(59.5)$ & 0.632 \\
\hline Age (year) & $70.0 \pm 13.1$ & $66.7 \pm 12.6$ & $73.4 \pm 12.6$ & $<0.001$ \\
\hline $\mathrm{BMI}\left(\mathrm{kg} / \mathrm{m}^{2}\right)$ & $23.2 \pm 4.1$ & $23.9 \pm 4.4$ & $22.4 \pm 3.7$ & $<0.001$ \\
\hline $\mathrm{AC}(\mathrm{cm})$ & $83.1 \pm 10.2$ & $85.7 \pm 9.4$ & $79.1 \pm 9.9$ & $<0.001$ \\
\hline \multicolumn{5}{|l|}{ Past history } \\
\hline Hypertension & $1,448(73.9)$ & $703(71.1)$ & $745(76.7)$ & 0.004 \\
\hline Diabetes mellitus & $542(27.7)$ & 324 (32.8) & $218(22.5)$ & $<0.001$ \\
\hline Hypercholesterolemia & $658(33.6)$ & $207(20.9)$ & 451 (46.4) & $<0.001$ \\
\hline Current smoker & $398(20.3)$ & $208(21.0)$ & $190(19.6)$ & 0.427 \\
\hline Atrial fibrillation & $512(26.1)$ & $210(21.2)$ & 302 (31.1) & $<0.001$ \\
\hline Old CVA & $546(27.8)$ & $218(22.0)$ & 328 (33.8) & $<0.001$ \\
\hline \multicolumn{5}{|l|}{ Previous medication } \\
\hline Antiplatelet & 709 (36.1) & 394 (39.8) & $315(32.4)$ & 0.001 \\
\hline Anticoagulant & $221(11.3)$ & $75(7.6)$ & $146(15.0)$ & $<0.001$ \\
\hline Lipid lowering agent & $503(25.7)$ & 279 (28.2) & $224(23.0)$ & 0.009 \\
\hline \multicolumn{5}{|l|}{ Stroke symptom } \\
\hline Total NIHSS score & $4[2-10]$ & $3[1-7]$ & $5[2-13]$ & $<0.001$ \\
\hline LOC responsiveness & $338(17.2)$ & $93(9.4)$ & $245(25.2)$ & $<0.001$ \\
\hline LOC questions & $527(26.8)$ & $178(17.9)$ & 349 (35.8) & $<0.001$ \\
\hline LOC commands & $364(18.5)$ & $147(14.8)$ & $217(22.3)$ & $<0.001$ \\
\hline Visual field defect & $382(19.4)$ & $198(20.0)$ & $184(18.9)$ & 0.549 \\
\hline Horizontal eye movement & $458(23.3)$ & $181(18.2)$ & $277(28.4)$ & $<0.001$ \\
\hline Facial weakness & $1,042(53)$ & $447(45.1)$ & $595(61.1)$ & $<0.001$ \\
\hline Arm weakness & $1,042(53.0)$ & $458(46.2)$ & $584(60.0)$ & $<0.001$ \\
\hline Leg weakness & $1,068(54.3)$ & $455(45.9)$ & $613(62.9)$ & $<0.001$ \\
\hline Sensory deficit & $807(41.0)$ & $311(31.4)$ & $496(50.9)$ & $<0.001$ \\
\hline Limb ataxia & $183(9.3)$ & $120(12.1)$ & $63(6.5)$ & $<0.001$ \\
\hline Aphasia & $472(24.0)$ & $191(19.3)$ & $281(28.9)$ & $<0.001$ \\
\hline Hemineglect & $429(21.8)$ & $117(11.8)$ & $312(32.0)$ & $<0.001$ \\
\hline Dysarthria & $1,339(68.1)$ & $659(66.4)$ & $680(69.8)$ & 0.107 \\
\hline \multicolumn{5}{|l|}{ Onset time } \\
\hline Weekday & $650(33.1)$ & $314(31.7)$ & $336(34.5)$ & 0.180 \\
\hline Daytime & $1,559(79.3)$ & $809(81.6)$ & $750(77.0)$ & 0.013 \\
\hline \multicolumn{5}{|l|}{ Transfer mode } \\
\hline EMS & $1,102(56.1)$ & $321(32.4)$ & 781 (80.2) & $<0.001$ \\
\hline Transfer from another hospital & $200(10.2)$ & $80(8.1)$ & $120(12.3)$ & 0.002 \\
\hline Reperfusion therapy & $246(12.5)$ & $120(12.1)$ & $126(12.9)$ & 0.574 \\
\hline IV tPA & $194(9.9)$ & $75(7.6)$ & $119(12.2)$ & $<0.001$ \\
\hline Endovascular therapy & $95(4.8)$ & $73(7.4)$ & $22(2.3)$ & $<0.001$ \\
\hline
\end{tabular}

Data are presented as number of patients $(\%)$, mean \pm standard deviation, or median [interquartile range].

YUHS, Yonsei University Health System; NCVC, National Cerebral and Cardiovascular Center; BMI, body mass index; AC, abdominal circumference; NIHSS, National Institutes of Health Stroke Scale; LOC, level of consciousness; EMS, emergency medical service.

lowering drugs; more severe stroke at presentation (higher NIHSS score); more frequent stroke onset during the nighttime; and more frequent transport by EMS or transfer from another hospital. While overall numbers of patients who received reperfusion therapy were not different between the two hospitals, IV tPA was more frequently used in NCVC and endovascular reperfusion therapy was more commonly performed in YUHS
(Table 1).

\section{Factors associated with early arrival}

In the univariate analysis of the entire study population, older age, atrial fibrillation, previous use of anticoagulants, higher NIHSS score, onset during daytime, and transport by EMS were significantly associated with early hospital arrival (Table 2 ). Transfer from another hospital was significantly associated with late hospital arrival. Presence of most stroke symptoms was related with early hospital arrival but limb ataxia was not. While atrial fibrillation, higher NIHSS score, onset during daytime, and transport by EMS were commonly associated with early arrival in each hospital, there were still some differences between the hospitals. Older age and non-smoking status were associated with early arrival only in the YUHS group. Transfer from another hospital was associated with late arrival only in the NCVC group.

In binary logistic regression analysis of the entire study population (adjusting for demographics and variables achieving a $P$ value of $<0.1$ in the univariate analyses), atrial fibrillation, higher initial NIHSS score, onset during daytime, and transport by EMS were independently associated with early arrival. In the binary logistic regression analysis of each hospital group, the factors associated with early arrival for each hospital were comparable to those of the entire study population, except that atrial fibrillation did not reach statistical significance in the NCVC group (Table 3). In the sensitivity analyses, which includes patients who had arrived at hospital within 24 hours of symptom onset, the results were comparable (Supplementary Tables 1-3).

\section{Discussion}

We investigated factors associated with early arrival of patients with stroke at two different stroke centers in Korea and Japan. This study showed that there were consistent factors related to early arrival despite the differences of patients' characteristics in two hospitals.

Although these two stroke centers are located in large metropolitan cities of countries in East Asia, the baseline demographics differed between them, which might be attributable to differences in hospital, regional, and national characteristics. As the NCVC is a highly specialized referral center for cerebrovascular and cardiovascular diseases even among tertiary centers, patients at the NCVC were older, more severely affected; more frequently transported by EMS or transferred from another hospital; and had more frequent histories of hypertension, atrial fibrillation, previous stroke, and previous use of anticoagulant therapy compared to patients from the YUHS, which is a general tertiary referral center. Meanwhile, higher body mass index and 
Table 2. Univariate model of early hospital arrival for the entire study population and for each hospital

\begin{tabular}{|c|c|c|c|c|c|c|c|c|c|}
\hline & \multicolumn{3}{|c|}{ Total $(n=1,966)$} & \multicolumn{3}{|c|}{ YUHS (n=992) } & \multicolumn{3}{|c|}{$\operatorname{NCVC}(n=974)$} \\
\hline & $\begin{array}{c}\text { Early arrival } \\
\text { group }(n=875)\end{array}$ & $\begin{array}{c}\text { Late arrival } \\
\text { group }(n=1,091)\end{array}$ & $P$ & $\begin{array}{c}\text { Early arrival } \\
\text { group }(n=423)\end{array}$ & $\begin{array}{c}\text { Late arrival } \\
\text { group }(n=569)\end{array}$ & $P$ & $\begin{array}{c}\text { Early arrival } \\
\text { group }(n=452)\end{array}$ & $\begin{array}{l}\text { Late arrival } \\
\text { group }(n=522)\end{array}$ & $P$ \\
\hline \multicolumn{10}{|l|}{ Demographics } \\
\hline Sex (male) & $520(59.4)$ & $660(60.6)$ & 0.596 & $243(57.4)$ & $357(63.0)$ & 0.079 & $277(61.3)$ & $303(58.0)$ & 0.305 \\
\hline Age (year) & $71.1 \pm 12.7$ & $69.2 \pm 13.3$ & 0.001 & $68.2 \pm 12.2$ & $65.7 \pm 12.9$ & 0.002 & $73.9 \pm 12.6$ & $73.0 \pm 12.7$ & 0.255 \\
\hline $\mathrm{BMI}\left(\mathrm{kg} / \mathrm{m}^{2}\right)$ & $23.1 \pm 3.7$ & $23.2 \pm 4.5$ & 0.501 & $23.8 \pm 3.5$ & $24.0 \pm 4.9$ & 0.598 & $22.4 \pm 3.7$ & $22.4 \pm 3.7$ & 0.992 \\
\hline $\mathrm{AC}(\mathrm{cm})$ & $82.8 \pm 10.3$ & $83.4 \pm 10.1$ & 0.310 & $85.6 \pm 9.5$ & $85.8 \pm 9.4$ & 0.641 & $79.0 \pm 10.2$ & $79.2 \pm 9.8$ & 0.731 \\
\hline \multicolumn{10}{|l|}{ Past history } \\
\hline Hypertension & $653(74.8)$ & $795(73.1)$ & 0.405 & $312(73.8)$ & 391 (69.1) & 0.108 & 341 (75.8) & $404(77.5)$ & 0.516 \\
\hline Diabetes mellitus & $227(26.0)$ & $315(29.0)$ & 0.143 & $134(31.7)$ & 190 (33.6) & 0.531 & $93(20.7)$ & $125(24.0)$ & 0.216 \\
\hline Hypercholesterolemia & $284(32.5)$ & $374(34.4)$ & 0.382 & $78(18.4)$ & $129(22.8)$ & 0.096 & 206 (45.8) & $245(47.0)$ & 0.698 \\
\hline Current smoker & $161(18.5)$ & $237(21.8)$ & 0.068 & $74(17.5)$ & $134(23.7)$ & 0.018 & 87 (19.4) & $103(19.8)$ & 0.878 \\
\hline Atrial fibrillation & 294 (33.7) & $218(20.1)$ & $<0.001$ & $130(30.7)$ & $80(14.1)$ & $<0.001$ & $164(36.4)$ & $138(26.5)$ & 0.001 \\
\hline Old CVA & $239(27.4)$ & $307(28.2)$ & 0.680 & $96(22.7)$ & $122(21.4)$ & 0.637 & $143(31.8)$ & $185(35.6)$ & 0.204 \\
\hline \multicolumn{10}{|l|}{ Previous medication } \\
\hline Antiplatelet agent & $315(36.0)$ & 394 (36.2) & 0.925 & $170(40.2)$ & 224 (39.6) & 0.845 & $145(32.2)$ & $170(32.6)$ & 0.874 \\
\hline Anticoagulant & $116(13.3)$ & $105(9.7)$ & 0.012 & $39(9.2)$ & $36(6.4)$ & 0.093 & $77(17.1)$ & $69(13.2)$ & 0.096 \\
\hline Lipid lowering agent & $224(25.6)$ & $279(25.7)$ & 0.985 & $121(28.6)$ & $158(27.9)$ & 0.811 & $103(22.8)$ & $121(23.2)$ & 0.887 \\
\hline \multicolumn{10}{|l|}{ Stroke symptom } \\
\hline Total NIHSS score & $6[2-15]$ & $3[1-7]$ & $<0.001$ & $5[2-14]$ & $3[1-5]$ & $<0.001$ & $7[3-17]$ & $4[2-11]$ & $<0.001$ \\
\hline LOC responsiveness & $203(23.2)$ & $135(12.4)$ & $<0.001$ & $65(15.4)$ & $28(4.9)$ & $<0.001$ & $138(30.5)$ & $107(20.5)$ & $<0.001$ \\
\hline LOC questions & 301 (34.4) & $226(20.7)$ & $<0.001$ & $116(27.4)$ & $62(10.9)$ & $<0.001$ & $185(40.9)$ & $164(31.4)$ & 0.002 \\
\hline LOC commands & $220(25.1)$ & $144(13.2)$ & $<0.001$ & $98(23.2)$ & $49(8.6)$ & $<0.001$ & $122(27.0)$ & $95(18.2)$ & 0.001 \\
\hline Visual field defect & $229(26.2)$ & $153(14.0)$ & $<0.001$ & $124(29.3)$ & $74(13.0)$ & $<0.001$ & $105(23.2)$ & $79(15.1)$ & 0.001 \\
\hline Horizontal eye movement & $304(34.7)$ & $154(14.1)$ & $<0.001$ & 132 (31.2) & $49(8.6)$ & $<0.001$ & $172(38.1)$ & $105(20.1)$ & $<0.001$ \\
\hline Facial weakness & $509(58.2)$ & $533(48.9)$ & $<0.001$ & $220(52.0)$ & 227 (39.9) & $<0.001$ & 289 (63.9) & 306 (58.6) & 0.090 \\
\hline Arm weakness & $523(59.8)$ & $519(47.6)$ & $<0.001$ & $236(55.8)$ & 222 (39) & $<0.001$ & $287(63.5)$ & $297(56.9)$ & 0.036 \\
\hline Leg weakness & $524(59.9)$ & $544(49.9)$ & $<0.001$ & $227(53.7)$ & $228(40.1)$ & $<0.001$ & $297(65.7)$ & $316(60.5)$ & 0.096 \\
\hline Sensory deficit & 427 (48.8) & $380(34.8)$ & $<0.001$ & $172(40.7)$ & $139(24.4)$ & $<0.001$ & $255(56.4)$ & 241 (46.2) & 0.001 \\
\hline Limb ataxia & $75(8.6)$ & $108(9.9)$ & 0.314 & $44(10.4)$ & $76(13.4)$ & 0.158 & 31 (6.90) & $32(6.1)$ & 0.645 \\
\hline Aphasia & $261(29.8)$ & $211(19.3)$ & $<0.001$ & $115(27.2)$ & $76(13.4)$ & $<0.001$ & $146(32.3)$ & $135(25.9)$ & 0.027 \\
\hline Hemineglect & $256(29.3)$ & $173(15.9)$ & $<0.001$ & 71 (16.8) & $46(8.1)$ & $<0.001$ & $185(40.9)$ & $127(24.3)$ & $<0.001$ \\
\hline Dysarthria & $628(71.8)$ & 711 (65.2) & 0.002 & $313(74.0)$ & 346 (60.8) & $<0.001$ & $315(69.7)$ & $365(69.9)$ & 0.937 \\
\hline \multicolumn{10}{|l|}{ Onset time } \\
\hline Weekday & $596(68.1)$ & $720(66.0)$ & 0.321 & 292 (69.0) & 386 (67.8) & 0.690 & $304(67.3)$ & 334 (64) & 0.284 \\
\hline Daytime & 764 (87.3) & $795(72.9)$ & $<0.001$ & 369 (87.2) & 440 (77.3) & $<0.001$ & 395 (87.4) & $355(68)$ & $<0.001$ \\
\hline \multicolumn{10}{|l|}{ Transfer mode } \\
\hline EMS & $604(69.0)$ & $498(45.6)$ & $<0.001$ & $199(47)$ & $122(21.4)$ & $<0.001$ & $405(89.6)$ & $376(72)$ & $<0.001$ \\
\hline Transfer from another hospital & $59(6.7)$ & $141(12.9)$ & $<0.001$ & $29(6.9)$ & $51(9.0)$ & 0.228 & $30(6.6)$ & $90(17.2)$ & $<0.001$ \\
\hline
\end{tabular}

Data are presented with number (\%), mean \pm standard deviation, or median [interquartile range].

YUHS, Yonsei University Health System; NCVC, National Cerebral and Cardiovascular Center; BMI, body mass index; AC, abdominal circumference; CVA, cerebrovascular accident; NIHSS, National Institutes of Health Stroke Scale; LOC, level of consciousness; EMS, emergency medical service.

abdominal circumference, and more frequent history of diabetes mellitus and previous use of antiplatelet agent and lipid lowering drugs in the YUHS patients compared to those from the NCVC may reflect some general features of Korea compared with Japan. During the last few decades, the prevalence of diabetes mellitus and metabolic syndrome has been rapidly increasing in Korea. ${ }^{12}$ Despite the rate of acute reperfusion therapy were not different between the two hospitals, IV tPA was more frequently used in NCVC, and endovascular treatment was more commonly used in YUHS. This difference might be partly related with the differ- ent reimbursement policy of national insurance service for IV tPA as well as the different regulation policy and availability regarding endovascular devices between the two countries. Time limit of IV tPA for reimbursement was extended from 3 hours to 4.5 hours at August 2012 in Japan, ${ }^{13}$ but not in Korea during the study enrollment period.

Despite the different baseline characteristics between the two stroke centers, several major factors associated with early hospital arrival were consistent. Among them, transport by EMS demonstrated important association with early arrival, as in pre- 
Table 3. Multivariate model of early hospital arrival for the entire study population and for each hospital

\begin{tabular}{|c|c|c|c|c|c|c|}
\hline & \multicolumn{2}{|c|}{ Total $(n=1,966)$} & \multicolumn{2}{|c|}{ YUHS (n=992) } & \multicolumn{2}{|c|}{$\operatorname{NCVC}(n=974)$} \\
\hline & OR [95\% Cl] & $P$ & OR $[95 \% \mathrm{Cl}]$ & $P$ & OR [95\% Cl] & $P$ \\
\hline Sex (male) & $1.156[0.941-1.420]$ & 0.168 & $1.019[0.751-1.382]$ & 0.903 & $1.308[0.987-1.734]$ & 0.062 \\
\hline Age & $0.995[0.987-1.003]$ & 0.242 & 1.000 [0.988-1.012] & 0.990 & 0.996 [0.985-1.007] & 0.497 \\
\hline Current smoker & 0.852 [0.660-1.100] & 0.219 & 0.852 [0.586-1.238] & 0.401 & - & \\
\hline Hypercholesterolemia & - & & $0.815[0.580-1.145]$ & 0.238 & - & \\
\hline Atrial fibrillation & $1.505[1.168-1.939]$ & 0.002 & $1.695[1.149-2.500]$ & 0.008 & $1.325[0.940-1.867]$ & 0.109 \\
\hline Previous anticoagulant & 0.861 [0.617-1.202] & 0.379 & 0.887 [0.504-1.559] & 0.677 & 0.970 [0.638-1.475] & 0.888 \\
\hline Total NIHSS score & $1.037[1.023-1.051]$ & $<0.001$ & 1.077 [1.052-1.103] & $<0.001$ & $1.018[1.002-1.035]$ & 0.031 \\
\hline Onset during daytime & $2.799[2.173-3.605]$ & $<0.001$ & 2.370 [1.620-3.468] & $<0.001$ & $3.255[2.306-4.594]$ & $<0.001$ \\
\hline EMS & $2.127[1.700-2.661]$ & $<0.001$ & $2.275[1.680-3.081]$ & $<0.001$ & 3.145 [1.754-5.639] & $<0.001$ \\
\hline Transfer from another hospital & 0.814 [0.567-1.169] & 0.265 & & & $1.078[0.536-2.170]$ & 0.833 \\
\hline
\end{tabular}

YUHS, Yonsei University Health System; NCVC, National Cerebral and Cardiovascular Center; OR, odds ratio; NIHSS, National Institutes of Health Stroke Scale; EMS, emergency medical service.

vious studies. ${ }^{47-10}$ Calling an EMS implies that the patient or bystander recognized the symptom of stroke as being urgent, and managed the situation properly. Contact with an EMS enables the appropriate delivery of the patient to the nearest hospital with facilities for acute stroke care.

In our study, the frequency of EMS use was much higher in the NCVC patients $(80.2 \%)$ compared to those from the YUHS (32.4\%). Previous studies using retrospective registry data from tertiary general hospitals in Japan have indicated the frequency of EMS use to be around $50 \%,{ }^{14,15}$ and one study using prospective survey data from 14 tertiary general hospitals in Korea has indicated a frequency of 36\% ${ }^{16,17}$ Higher rates of EMS use in Japan, despite EMS being free in both countries, may be associated with better knowledge of act on stroke. ${ }^{16,18}$ Therefore, public education is important for increasing the use of EMS and reducing prehospital delays. ${ }^{17-20}$ However, the $80 \%$ EMS use of the NCVC in our study was even higher than previous statistics from Japan. It is likely that EMS personnel may prefer to deliver patients with a suspected stroke to a highly specialized hospital like the NCVC. This finding suggests that the awareness of which hospitals have a stroke center by EMS personnel is important for appropriate dispatch, particularly in metropolitan cities with many hospitals.

Greater stroke severity represented by a higher initial NIHSS score is a well-known factor associated with early arrival, ${ }^{4,710}$ and was confirmed by our analysis. Of note, while most of stroke symptoms were related with early hospital arrival, limb ataxia was not. This may reflect the suboptimal public awareness regarding limb ataxia as a stroke symptom. ${ }^{21}$ Onset during daytime was associated with early hospital arrival. This might be partly attributable to delayed recognition of stroke symptoms by a witness when severe stroke incapacitates people during the nighttime. However, waiting until the morning may also cause delays after nighttime onset. This aspect should be addressed in public education.
The association between atrial fibrillation and early hospital arrival was also noted in our results, as in most previous reports. ${ }^{9,17}$ Stroke caused by cardiac embolism is usually more severe and sudden in onset. ${ }^{22}$ These characteristics may cause patients or witnesses to seek medical assistance earlier. However, the $P$ values for atrial fibrillation did not reach the level of statistical significance after adjusting for confounding factors in the NCVC patients. This might reflect low power of NCVC subgroup rather than true insignificance. While the reason is uncertain, male sex tended to be related with early hospital arrival only in NCVC.

The strength of this study is that we analyzed data for a relatively large sample from two distinct hospitals located in different countries. Our study is also valuable because it is one of only a few reports about this issue in East Asian populations. However, the study has some limitations that need to be addressed. Firstly, factors known to affect prehospital delays, such as educational, socioeconomic, and personal attributes were not investigated in the current study. In addition, some variables were not available from the records, such as the distance from the place where the stroke occurred to the hospital, which might be helpful in interpreting the results. Secondly, because the two hospitals studied were tertiary referral centers located in urban areas of each country, the findings of this study cannot be generalized. These limitations should be considered when interpreting the study results.

In conclusion, transport by EMS, daytime onset, atrial fibrillation, and higher initial NIHSS scores were consistently associated with early hospital arrival regardless of the country or hospital characteristics. Despite transport by EMS is the only directly modifiable factor, education focused on the characteristics of late arrival patients might promote early hospital arrival and improve stroke outcome. 


\section{References}

1. Jauch EC, Saver JL, Adams HP Jr, Bruno A, Connors JJ, Demaerschalk BM, et al. Guidelines for the early management of patients with acute ischemic stroke: a guideline for healthcare professionals from the American Heart Association/American Stroke Association. Stroke 2013;44:870-947.

2. Berkhemer OA, Fransen PS, Beumer D, van den Berg LA, Lingsma HF, Yoo AJ, et al. A randomized trial of intraarterial treatment for acute ischemic stroke. $N$ Engl J Med 2015;372: 11-20.

3. de Los Ríos la Rosa F, Khoury J, Kissela BM, Flaherty ML, Alwell $\mathrm{K}$, Moomaw CJ, et al. Eligibility for intravenous recombinant tissue-type plasminogen activator within a population: the effect of the European Cooperative Acute Stroke Study (ECASS) III trial. Stroke 2012;43:1591-1595.

4. Jin $\mathrm{H}$, Zhu S, Wei JW, Wang J, Liu M, Wu Y, et al. Factors associated with prehospital delays in the presentation of acute stroke in urban China. Stroke 2012;43:362-370.

5. Khatri P, Yeatts SD, Mazighi M, Broderick JP, Liebeskind DS, Demchuk AM, et al. Time to angiographic reperfusion and clinical outcome after acute ischaemic stroke: an analysis of data from the Interventional Management of Stroke (IMS III) phase 3 trial. Lancet Neurol 2014;13:567-574.

6. Emberson J, Lees KR, Lyden P, Blackwell L, Albers G, Bluhmki E, et al. Effect of treatment delay, age, and stroke severity on the effects of intravenous thrombolysis with alteplase for acute ischaemic stroke: a meta-analysis of individual patient data from randomised trials. Lancet 2014;384:1929-1935.

7. Morris DL, Rosamond W, Madden K, Schultz C, Hamilton S. Prehospital and emergency department delays after acute stroke: the Genentech Stroke Presentation Survey. Stroke 2000;31: 2585-2590.

8. Derex L, Adeleine P, Nighoghossian N, Honnorat J, Trouillas P. Factors influencing early admission in a French stroke unit. Stroke 2002;33:153-159.

9. Faiz KW, Sundseth A, Thommessen B, Rønning OM. Prehospital delay in acute stroke and TIA. Emerg Med J 2013;30:669674.

10. Fassbender K, Balucani C, Walter S, Levine SR, Haass A, Grotta J. Streamlining of prehospital stroke management: the golden hour. Lancet Neurol 2013;12:585-596.
11. Gorelick PB. Primary and comprehensive stroke centers: history, value and certification criteria. J Stroke 2013;15:78-89.

12. Lim S, Shin H, Song JH, Kwak SH, Kang SM, Won Yoon J, et al. Increasing prevalence of metabolic syndrome in Korea: the Korean National Health and Nutrition Examination Survey for 1998-2007. Diabetes Care 2011;34:1323-1328.

13. Minematsu K, Toyoda K, Hirano T, Kimura K, Kondo R, Mori $\mathrm{E}$, et al. Guidelines for the intravenous application of recombinant tissue-type plasminogen activator (alteplase), the second edition, October 2012: a guideline from the Japan Stroke Society. J Stroke Cerebrovasc Dis 2013;22:571-600.

14. Inatomi Y, Yonehara T, Hashimoto Y, Hirano T, Uchino M. Prehospital delay in the use of intravenous rt-PA for acute ischemic stroke in Japan. J Neurol Sci 2008;270:127-132.

15. Yanagida T, Fujimoto S, Inoue T, Suzuki S. Causes of prehospital delay in stroke patients in an urban aging society. J Clin Gerontol Geriatr 2014;5:77-81.

16. Hong KS, Bang OY, Kim JS, Heo JH, Yu KH, Bae HJ, et al. Stroke statistics in Korea: part II stroke awareness and acute stroke care, a report from the Korean Stroke Society and Clinical Research Center for Stroke. J Stroke 2013;15:67-77.

17. Kim YS, Park SS, Bae HJ, Cho AH, Cho YJ, Han MK, et al. Stroke awareness decreases prehospital delay after acute ischemic stroke in Korea. BMC Neurol 2011;11:2.

18. Miyamatsu N, Okamura T, Nakayama H, Toyoda K, Suzuki K, Toyota A, et al. Public awareness of early symptoms of stroke and information sources about stroke among the general Japanese population: the Acquisition of Stroke Knowledge Study. Cerebrovasc Dis 2013;35:241-249.

19. Miyashita F, Yokota C, Nishimura K, Amano T, Inoue Y, Shigehatake $Y$, et al. The effectiveness of a stroke educational activity performed by a schoolteacher for junior high school students. J Stroke Cerebrovasc Dis 2014;23:1385-1390.

20. Sakamoto Y, Yokota C, Miyashita F, Amano T, Shigehatake Y, Oyama S, et al. Effects of stroke education using an animated cartoon and a manga on elementary school children. J Stroke Cerebrovasc Dis 2014;23:1877-1881.

21. Kim YS, Park SS, Bae HJ, Heo JH, Kwon SU, Lee BC, et al. Public awareness of stroke in Korea: a population-based national survey. Stroke 2012;43:1146-1149.

22. Ferro JM. Cardioembolic stroke: an update. Lancet Neurol 2003; 2:177-188. 
Supplementary Table 1. Baseline characteristics of patients who arrived within 24 hours

\begin{tabular}{|c|c|c|c|c|}
\hline & Total $(n=1,629)$ & YUHS ( $n=808)$ & $\operatorname{NCVC}(n=821)$ & $P$ \\
\hline \multicolumn{5}{|l|}{ Demographics } \\
\hline Sex (male) & $965(59.2)$ & 483 (59.8) & $482(58.7)$ & 0.661 \\
\hline Age (year) & $70.3 \pm 13.1$ & $67.0 \pm 12.6$ & $73.6 \pm 12.8$ & $<0.001$ \\
\hline $\mathrm{BMI}\left(\mathrm{kg} / \mathrm{m}^{2}\right)$ & $23.1 \pm 3.6$ & $23.8 \pm 3.3$ & $22.4 \pm 3.7$ & $<0.001$ \\
\hline $\mathrm{AC}(\mathrm{cm})$ & $83.1 \pm 10.2$ & $85.9 \pm 9.4$ & $78.8 \pm 9.9$ & $<0.001$ \\
\hline \multicolumn{5}{|l|}{ Past history } \\
\hline Hypertension & $1,197(73.6)$ & $580(71.8)$ & $617(75.4)$ & 0.095 \\
\hline Diabetes mellitus & 426 (26.2) & $256(31.7)$ & $170(20.8)$ & $<0.001$ \\
\hline Hypercholesterolemia & 542 (33.3) & $170(21.0)$ & $372(45.5)$ & $<0.001$ \\
\hline Current smoker & $317(19.5)$ & $154(19.1)$ & $163(20.0)$ & 0.650 \\
\hline Atrial fibrillation & 460 (28.3) & $190(23.5)$ & $270(33.0)$ & $<0.001$ \\
\hline Old CVA & $448(27.6)$ & $178(22.0)$ & 270 (32.9) & $<0.001$ \\
\hline \multicolumn{5}{|l|}{ Previous medication } \\
\hline Antiplatelet & $581(41.9)$ & $316(39.1)$ & $265(45.9)$ & 0.011 \\
\hline Anticoagulant & $195(12.0)$ & $66(8.2)$ & $129(15.8)$ & $<0.001$ \\
\hline Lipid lowering agent & $414(25.4)$ & $233(28.8)$ & $181(22.1)$ & 0.002 \\
\hline \multicolumn{5}{|l|}{ Stroke symptom } \\
\hline Total NIHSS score & $4[2-12]$ & $4[1-3]$ & $6[2-15]$ & $<0.001$ \\
\hline LOC responsiveness & $302(18.5)$ & $88(10.9)$ & $214(26.1)$ & $<0.001$ \\
\hline LOC questions & $470(28.8)$ & $163(20.1)$ & 307 (37.4) & $<0.001$ \\
\hline LOC commands & 334 (20.5) & $137(16.9)$ & $197(24.0)$ & $<0.001$ \\
\hline Visual field defect & $344(21.1)$ & $179(22.1)$ & $165(20.1)$ & 0.322 \\
\hline Horizontal eye movement & $429(26.3)$ & $174(21.5)$ & $255(31.1)$ & $<0.001$ \\
\hline Facial weakness & $892(54.7)$ & $384(47.4)$ & $508(61.9)$ & $<0.001$ \\
\hline Arm weakness & $904(55.4)$ & $396(48.9)$ & $508(61.9)$ & $<0.001$ \\
\hline Leg weakness & $916(56.2)$ & $386(47.7)$ & $530(64.6)$ & $<0.001$ \\
\hline Sensory deficit & $708(43.4)$ & $274(33.8)$ & $434(52.9)$ & $<0.001$ \\
\hline Limb ataxia & $150(9.2)$ & $100(12.3)$ & $50(6.1)$ & $<0.001$ \\
\hline Aphasia & $410(25.1)$ & $169(20.9)$ & $241(29.4)$ & $<0.001$ \\
\hline Hemineglect & $391(24)$ & $106(13.1)$ & $285(34.7)$ & $<0.001$ \\
\hline Dysarthria & $1,131(69.3)$ & $550(67.9)$ & $581(70.8)$ & 0.209 \\
\hline \multicolumn{5}{|l|}{ Onset time } \\
\hline Weekday & $1,108(67.9)$ & $564(69.6)$ & $544(66.3)$ & 0.145 \\
\hline Daytime & $1,286(78.8)$ & $651(80.4)$ & $635(77.3)$ & 0.135 \\
\hline \multicolumn{5}{|l|}{ Transfer mode } \\
\hline EMS & $973(59.7)$ & $288(35.6)$ & $685(83.4)$ & $<0.001$ \\
\hline Transfer from another hospital & $153(9.4)$ & $70(8.6)$ & $83(10.1)$ & 0.309 \\
\hline Reperfusion therapy & $238(14.6)$ & $117(14.4)$ & $121(14.7)$ & 0.867 \\
\hline IV tPA & $191(11.7)$ & $74(9.2)$ & $117(14.3)$ & 0.001 \\
\hline Endovascular therapy & $90(5.5)$ & $71(8.8)$ & $19(2.3)$ & $<0.001$ \\
\hline
\end{tabular}

Data are presented as number of patients $(\%)$, mean \pm standard deviation, or median [interquartile range].

YUHS, Yonsei University Health System; NCVC, National Cerebral and Cardiovascular Center; BMI, body mass index; AC, abdominal circumference; NIHSS, National Institutes of Health Stroke Scale; LOC, level of consciousness; EMS, emergency medical service. 
Supplementary Table 2. Univariate model of early hospital arrival for the entire study population and for each hospital in patients arrived within 24 hours

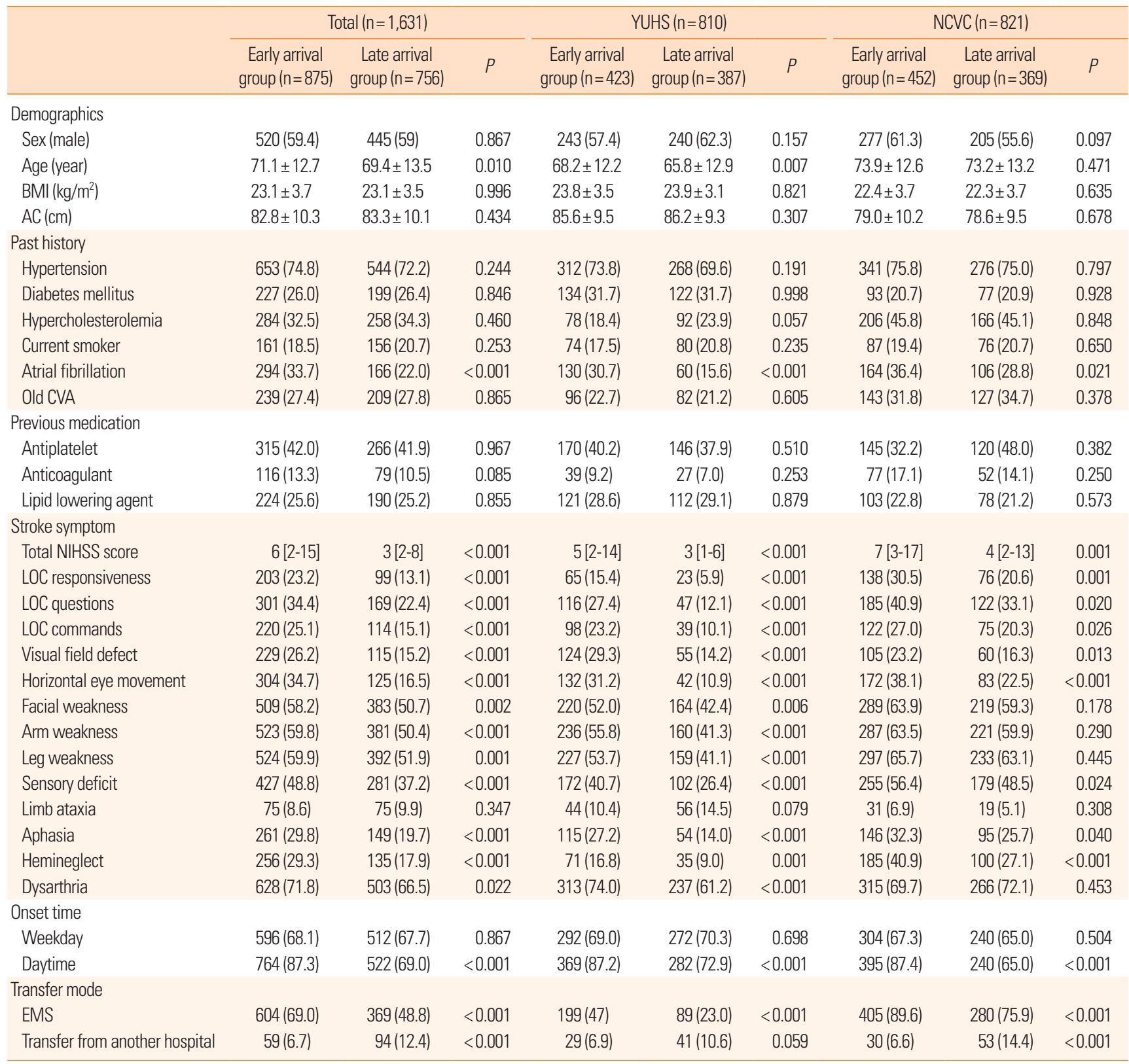

Data are presented with number $(\%)$, mean \pm standard deviation, or median [interquartile range].

YUHS, Yonsei University Health System; NCVC, National Cerebral and Cardiovascular Center; BMI, body mass index; AC, abdominal circumference; CVA, cerebrovascular accident; NIHSS, National Institutes of Health Stroke Scale; LOC, level of consciousness; EMS, emergency medical service. 
Supplementary Table 3. Multivariate model of early hospital arrival for the entire study population and for each hospital in patients arrived within 24 hours

\begin{tabular}{|c|c|c|c|c|c|c|}
\hline & Total (n & & YUHS & & NCVC & \\
\hline & $\mathrm{OR}[95 \% \mathrm{Cl}]$ & $P$ & $\mathrm{OR}[95 \% \mathrm{Cl}]$ & $P$ & $\mathrm{OR}[95 \% \mathrm{Cl}]$ & $P$ \\
\hline Sex (male) & $1.196[0.962-1.485]$ & 0.107 & 1.010 [0.736-1.388] & 0.949 & $1.433[1.054-1.948]$ & 0.022 \\
\hline Age & $0.997[0.988-1.005]$ & 0.431 & $1.002[0.989-1.014]$ & 0.814 & 0.996 [0.984-1.008] & 0.488 \\
\hline Hypercholesterolemia & - & & $0.785[0.543-1.135]$ & 0.198 & - & \\
\hline Atrial fibrillation & 1.430 [1.089-1.878] & 0.010 & $1.588[1.082-2.331]$ & 0.018 & 1.202 [0.858-1.684] & 0.286 \\
\hline Previous anticoagulant & $0.838[0.587-1.196]$ & 0.330 & - & & - & \\
\hline Total NIHSS score & 1.031 [1.016-1.046] & $<0.001$ & 1.072 [1.043-1.101] & $<0.001$ & 1.016 [0.998-1.034] & 0.084 \\
\hline Onset during daytime & $3.235[2.486-4.210]$ & $<0.001$ & 2.899 [1.950-4.309] & $<0.001$ & 3.673 [2.556-5.279] & $<0.001$ \\
\hline EMS & $1.956[1.532-2.497]$ & $<0.001$ & $2.031[1.430-2.886]$ & $<0.001$ & $2.845[1.517-5.336]$ & 0.001 \\
\hline Transfer from another hospital & $0.845[0.571-1.249]$ & 0.398 & $0.600[0.332-1.084]$ & 0.091 & 1.259 [0.590-2.689] & 0.551 \\
\hline
\end{tabular}

YUHS, Yonsei University Health System; NCVC, National Cerebral and Cardiovascular Center; OR, odds ratio; NIHSS, National Institutes of Health Stroke Scale; EMS, emergency medical service. 